\title{
Performance, intestinal histomorphology and bone composition of broiler chickens fed diets supplemented with genistein
}

\author{
M. Glisic ${ }^{1 \#, ~ M . ~ B o s k o v i c ~}{ }^{1}$, M. Z. Baltic ${ }^{1}$, D. Sefer ${ }^{2}$, A. Radovanovic ${ }^{3}$, V. Djordjevic ${ }^{4}$, M. Raseta ${ }^{4}$ \\ \& R. Markovic ${ }^{2}$ \\ ${ }^{1}$ Department of Food Hygiene and Technology, Faculty of Veterinary Medicine, University of Belgrade, Belgrade, Serbia \\ ${ }^{2}$ Department of Nutrition and Botany, Faculty of Veterinary Medicine, University of Belgrade, Belgrade, Serbia \\ ${ }^{3}$ Department of Histology and Embryology, Faculty of Veterinary Medicine, University of Belgrade, Belgrade, Serbia \\ ${ }^{4}$ Institute of Meat Hygiene and Technology, Belgrade, Serbia
}

(Received 2 October 2019; Accepted 4 January 2020; First published online 25 April 2020)

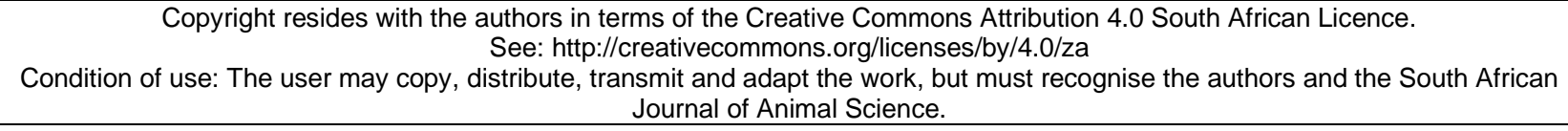
Journal of Animal Science.

\begin{abstract}
The effect of dietary genistein on performance, intestinal morphology, caecal Lactobacillus spp. count, and tibia composition in broiler chickens after 21 and 37 days of feeding was investigated. A total of 360 Cobb 500 broiler chickens ( 21 days old) were randomly allocated to five treatments with six replicates of 12 birds each. They were fed a basal diet (C) or a basal diet supplemented with 200 (T1), 400 (T2), 600 (T3) and 800 (T4) mg genistein/kg of feed. Genistein supplementation did not affect feed intake, but improved bodyweight, weight gain and feed conversion ratio (FCR) after 21 days, while $600 \mathrm{mg} / \mathrm{kg}$ led to a significant increase in FCR after 37 days of feeding. Plasma triglyceride level decreased with dietary genistein after 21 days, while increases were found in T3 and T4 groups after prolonged supplementation. Significantly improved duodenal and jejunal villus length and width, crypt depth and villus/crypt ratio were observed after the first and the second finishing periods, respectively, while adverse effects were found in the ileum for both periods. At 42 days old, greater spleen and heart weights were measured in broilers fed diets with $800 \mathrm{mg} / \mathrm{kg}$ than in other broiler groups. The shorter genistein supplementation period (21 days) of 200 and $400 \mathrm{mg} / \mathrm{kg}$ had a positive effect on tibia wet weight, ash and calcium (Ca) content, while 37 days of the higher genistein doses administered to the T2, T3 and T4 birds significantly increased caecal lactic acid bacteria (LAB) counts. Thus, recommended doses should not exceed $400 \mathrm{mg} / \mathrm{kg}$.
\end{abstract}

\footnotetext{
Keywords: broiler performance, blood triglyceride, Lactobacillus, prolonged fattening, small intestinal morphology

\#Corresponding author: glisic.mica@gmail.com
}

\section{Introduction}

Phytogenic compounds from plants are considered one of the most effective solutions to inefficiencies in poultry production (Wallace et al., 2010). Over the last two decades, substantial interest has arisen in bioflavonoids, a group of secondary plant metabolites, as an alternative to growth-promoting antibiotics in poultry feedstuffs (Kamboh et al., 2015; Kamboh et al., 2019).

Isoflavones are a subclass of flavonoids and are mostly in the form of glycosidic conjugates, which are widely distributed in leguminous plant foods (Rasouli \& Jahanian, 2015; Zhu et al., 2015). Numerous studies have demonstrated the beneficial activities of isoflavones, including maintaining and improving bird health, enhancing performance, promoting, antioxidant, anti-inflammatory, antibacterial, and immunomodulatory effects, exhibiting estrogenic-like properties, up-regulating metabolic parameters, increasing bone mineralization, and improving meat and egg quality (Onderci et al., 2004; Jiang et al., 2007; Sahin et al., 2007; Kamboh \& Zhu, 2013a; lqbal et al., 2014; Kamboh \& Zhu, 2014; Kamboh et al., 2015; Rasouli \& Jahanian, 2015; Rasouli \& Jahanian; 2019).

Genistein, the second soy isoflavone in importance and occurrence after daidzein, is present in soybased food at concentrations from 0.2 to $1 \mathrm{mg} / \mathrm{g}$ (Ganai \& Faroogi, 2015). Because of the proven healthpromoting effects of genistein in animals and humans, purified and combined commercial preparations are available as feed additives and nutritional supplements with up to six times greater amounts of genistein than in foods (Payne et al., 2001; Clavel et al., 2005; Markovic et al., 2015; Shiralinezhad \& Shakouri, 2017). 
Because genistein, unlike other isoflavonoids, has a high therapeutic index, it has become the target compound for poultry dietary investigations, although at a variety of supplement dosages (Dixon \& Ferreira, 2002; Onderci et al., 2004; Kamboh \& Zhu, 2013a; Kamboh \& Zhu, 2014; lqbal et al., 2014; Lv et al., 2018; Rasouli \& Jahanian, 2019).

Previous studies investigated the effect of genistein supplementation in broiler diets on growth and intestinal parameters during six weeks of fattening, but results were inconsistent (Kamboh \& Zhu, 2013a; lqbal et al., 2014; Kamboh \& Zhu, 2014; Rasouli \& Jahanian, 2015; Lv et al., 2018; Rasouli \& Jahanian, 2019). Furthermore, to the best of the authors' knowledge, data are not available on the impact of purified genistein supplement in diets of broilers older than three weeks. Considering genistein's estrogenic activity (Setchell \& Cassidy, 1999), and the impact of dose and birds' age on its effectiveness (lqbal et al., 2014), the aim of this study was to examine the effect of differing genistein supplementation levels on growth performance, cholesterol and triglyceride plasma levels, small intestinal morphology, caecal LAB population, internal organ weights, and tibia $\mathrm{Ca}$ and phosphorus $(\mathrm{P})$ levels in the late fattening phase (birds were 42 days old), and after extended fattening (birds were 58 days old).

\section{Materials and Methods}

The experiment protocols and procedures were approved by the Veterinary Directorate of the Serbian Ministry of Agriculture, Forestry and Water Management (Approval No. 119-01-51/14/2017-09) and the Institutional Animal Care and Use Committee of the Faculty of Veterinary Medicine, University of Belgrade.

Animals were fed the experimental diet supplemented with genistein as a $99.6 \%$ pure extract obtained from the roots of Sophora subprostrata Chun et T. Chen and Genista tinctoria L. (Xi'AnHuilin Bio-Tech Co., Ltd., Xian, Shaanxi, P.R. China). The purity of the extract was determined by dissolving it in methanol and using the HPLC-DAD-ESI-MS/MS technique (Orčić et al., 2014) (Figure 1).

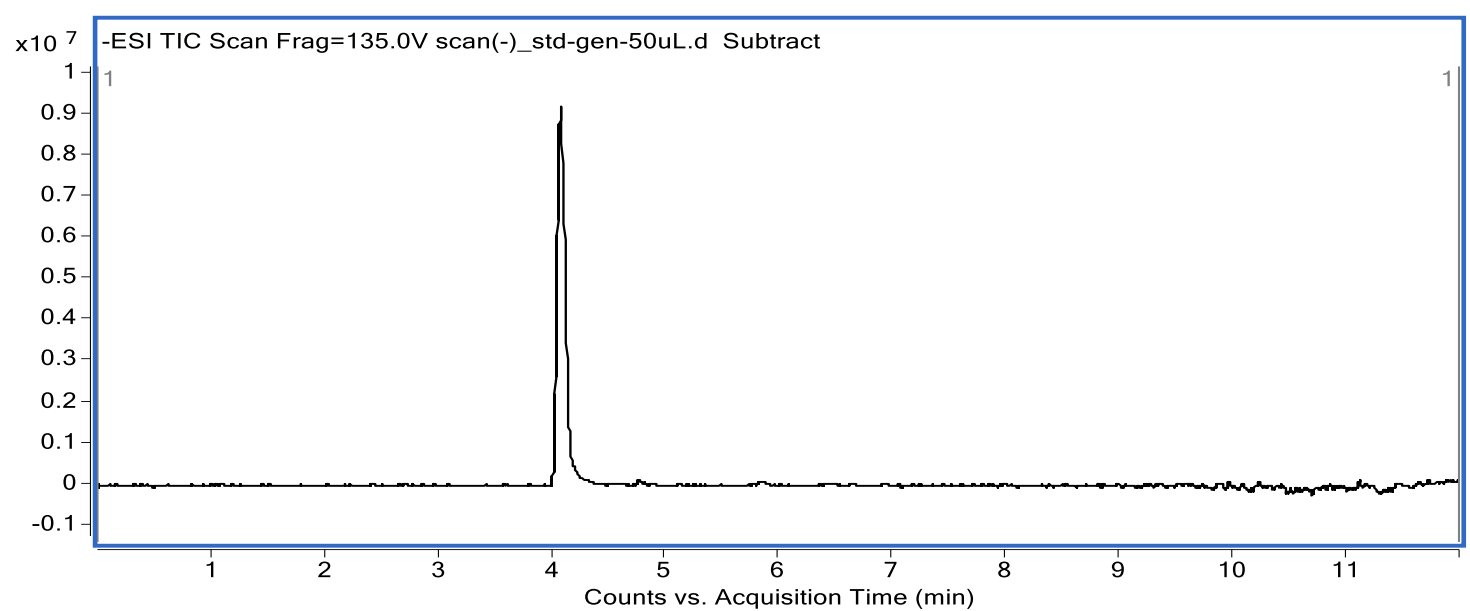

Figure 1 Liquid chromatography-mass spectrometry chromatogram of the genistein extract obtained in electrospray ionization negative mode

One-day-old mixed sex Cobb 500 broiler chickens with an average initial weight of $44.11 \mathrm{~g}$ were purchased from a commercial hatchery and raised up to 21 days old, during which time they were fed with standard starter ( 1 - 10 days; crumbled pellets) and grower (11-20 days; $1 \mathrm{~cm}$ pellets) diets with free access to feed and water and continuous lighting. At 21 days old, a total of 360 broiler chickens were weighed and allocated so that weight distributions were similar among experimental groups, that is, five treatments with six replicates. Thirty pens at $3 \mathrm{~m}^{2}$ with concrete floors were covered with wood shavings as litter to give 12 birds in each replicate. Birds were reared according to the guidelines set by the Cobb broiler management guide (Vantress, 2012). The basal corn-soybean meal diet was prepared to meet the nutrient requirements of the broilers (NRC, 1994). From 21 days to 58 days, the birds received common finisher feed mixtures $(1 \mathrm{~cm}$ pellets) supplemented with 0 (C), 200 (T1), 400 (T2), 600 (T3), and 800 (T4) mg genistein/kg feed. The study consisted of two periods. The first lasted 21 days (until day 42 of fattening), and the second 37 days (until day 58 of fattening). The basal diets for three growth phases are reported in Table 1.

Feed samples were ground, passed through a $0.5-\mathrm{mm}$ sieve, and analysed for moisture (ISO 6496:1999), total ash (ISO 5984:2002), crude protein (ISO 5983-1:2005), total lipids (ISO 6492:1999), crude fibre (ISO 6865:2000), calcium (ISO 6490-1:1985), and phosphorus content (ISO 6491:1998) (Table 1). 
Bodyweights were recorded individually on days 1,11 (average bodyweight $343.1 \mathrm{~g}$ ), 21, 42, and 58, and total feed intake was measured on days 42 and 58 according to the discarded feed leftovers. Bodyweight gain and feed conversion ratio for these periods were calculated using this data.

Table 1 Ingredient composition, calculated and chemical analysis of the experimental diets for broiler chickens

\begin{tabular}{|c|c|c|c|}
\hline & Starter & Grower & Finisher \\
\hline \multicolumn{4}{|l|}{ Ingredients (\%) } \\
\hline Maize & 50.85 & 44.15 & 44.95 \\
\hline Wheat & & 10.00 & 15.00 \\
\hline Soy grits & 15.00 & 17.00 & 20.00 \\
\hline Soybean meal (CP 44\%) & 12.40 & 1.00 & 1.00 \\
\hline Soybean cake (CP $41.5 \%)$ & 17.00 & 23.30 & 14.70 \\
\hline Monocalcium phosphate & 1.20 & 1.00 & 0.90 \\
\hline Chalk & 1.60 & 1.60 & 1.60 \\
\hline Salt & 0.35 & 0.35 & 0.35 \\
\hline Premix $^{1}$ & 1.00 & 1.00 & 1.00 \\
\hline Lysine & 0.20 & 0.20 & 0.10 \\
\hline Methionine & 0.20 & 0.20 & 0.20 \\
\hline Adsorbent & 0.20 & 0.20 & 0.20 \\
\hline Total & 100.0 & 100.0 & 100.0 \\
\hline \multicolumn{4}{|l|}{ Calculated analyses (\%) } \\
\hline$A M E_{n}(M J / k g)$ & 12.64 & 12.96 & 13.22 \\
\hline Crude protein & 22.68 & 21.80 & 19.05 \\
\hline Calcium & 1.08 & 1.02 & 1.08 \\
\hline Phosphorus & 0.61 & 0.58 & 0.71 \\
\hline Lysine & 1.49 & 1.42 & 1.10 \\
\hline Methionine + cysteine & 0.84 & 0.83 & 0.82 \\
\hline Tryptophan & 0.31 & 0.28 & 0.22 \\
\hline \multicolumn{4}{|l|}{ Chemical composition (\%) } \\
\hline Moisture & 12.61 & 13.32 & 10.54 \\
\hline Total ash & 5.32 & 5.20 & 5.11 \\
\hline Crude protein & 22.40 & 20.85 & 18.19 \\
\hline Total lipids & 6.89 & 7.90 & 6.48 \\
\hline Crude fibre & 2.74 & 3.39 & 2.59 \\
\hline Calcium & 0.85 & 0.77 & 0.76 \\
\hline Phosphorus & 0.67 & 0.58 & 0.56 \\
\hline $\mathrm{NFE}^{2}$ & 50.04 & 49.35 & 57.09 \\
\hline
\end{tabular}

${ }^{1}$ vitamin A $15000 \mathrm{IU}$; vitamin D3 $5000 \mathrm{IU}$; vitamin E $80 \mathrm{IU}$; nicotinic acid $62.5 \mathrm{mg}$; pantothenic acid $10 \mathrm{mg}$; folic acid 1.25 mg; d-biotin $0.10 \mathrm{mg}$; zinc $80 \mathrm{mg}$; manganese $120 \mathrm{mg}$; iron $78.5 \mathrm{mg}$; copper $19.92 \mathrm{mg}$; cobalt $1.4 \mathrm{mg}$; selenium $2.2 \mathrm{mg}$; antioxidant $100 \mathrm{mg}$

2 Nitrogen-free extract

At the end of each experimental period (birds were 42 and 58 days old), the feed was withdrawn for 12 hours. After weighing, 36 randomly selected broilers per treatment (six per replicate) were electrically stunned and slaughtered by severance of the jugular veins. Blood samples $(8 \mathrm{~mL})$ of fasting broilers were collected in serum non-heparinized tubes. Within one hour, these were centrifuged at $3000 \times g$ for $15 \mathrm{~min}$ and serum was separated. The concentrations of triglyceride and total cholesterol in the serum samples 
were analysed using colorimetric methods with an automatic biochemical analyser (RA-1000, Bayer Corp., Tarrytown, NY, USA). After carcass evisceration by trained personnel, the adhering tissue was removed from liver, spleen, heart, and these and the left tibiae were weighed. Organ weight was expressed as a percentage of live weight at the same age.

Immediately after slaughter, for both experimental periods, the gastrointestinal tracts of 18 birds per treatment (three per pen) were removed and segments approximately one centimetre long were taken from the middle part of duodenum, jejunum and ileum, flushed in physiological saline, and fixed in neutral formalin (10\% formalin (37 - 40\%), $\mathrm{NaH}_{2} \mathrm{PO} 4 \cdot \mathrm{H}_{2} \mathrm{O} 4.0 \mathrm{~g}$, and $\mathrm{NaHPO}_{4} \cdot \mathrm{H}_{2} \mathrm{O} 6.5 \mathrm{~g}$ ) solution for 24 hours. After fixation and shaping, intestinal samples (one sample for each of the three intestinal segments per bird) were dehydrated in increasing concentrations of ethyl alcohol, cleared with xylene, infiltrated with paraffin and embedded in paraffin blocks. Sections $5 \mu \mathrm{m}$ in thickness (three cross-sections from each sample) were placed on glass slides and stained with routine Mayer's haematoxylin and eosin procedure, and with a combination of periodic acid Schiff's stain and Alcian blue (PAS-AB) (Yamabayashi et al., 1987; Smirnov et al., 2005). Histological sections were examined using a light microscope Olympus BX53 with the objective magnifications $x 4$ and $x 10$. On each cross-section, 10 points were selected for microscopic investigation using Olympus cellSens software (Olympus Life Science Solutions, Tokyo, Japan). These measurements were taken: the villus height and width, and cryptal depth, which were also used to calculate villus height/crypt depth ratio (VCR) for each intestinal segment (duodenum, jejunum and ileum) (Aptekmann et al., 2001).

At the age of 42 and 58 days, one bird from each replicate was randomly selected for sampling to determine caecal LAB count. After slaughter, the intestinal tracts were excised and the contents from the cecum were immediately collected aseptically into a sterile plastic container and transported under cold conditions to the laboratory. Approximately $1 \mathrm{~g}$ of digesta from each sample was mixed with $9 \mathrm{~mL}$ of sterile physiological saline solution $(0.9 \% \mathrm{NaCl})$ and homogenized for 3 min using an Ultra-Turrax. These homogenates were serially diluted from $10^{-2}$ to $10^{-9}$. To enumerate Lactobacillus spp., $0.1 \mathrm{~mL}$ of appropriately diluted suspension was inoculated directly onto the surface of the agar plate (MRS, Hi Media, India) followed by incubation at $30^{\circ} \mathrm{C}$ for 72 hours in anaerobic conditions (Anaerocult A, Merck, Darmstadt, Germany). Results were expressed as log colony forming unit (CFU) per gram of cecal digesta.

After separating the drumsticks with thighs from the carcasses, all soft tissues and cartilaginous caps were removed from the left tibiae (six birds per pen) and the bones were kept frozen in plastic bags at $-20{ }^{\circ} \mathrm{C}$ until analysis for mineral content. The tibiae were defatted, dried at $15^{\circ} \mathrm{C}$ and combusted at $600{ }^{\circ} \mathrm{C}$ for 8 hours to determine ash percentage. Calcium content was measured with flame atomic absorption spectrometry (ISO 6869:2000) using an atomic absorption spectrophotometer (Perkin-Elmer Analyst 700 MHS, PerkinElmer Life and Analytical Science, Connecticut, United States), while P content was determined by the spectrophotometric method (ISO 6491:1998).

These data were analysed with one-way ANOVA using SPSS 20.0 (IBM, Chicago, IL, USA). The statistical differences between groups were determined with Tukey's post hoc multiple comparisons test. Orthogonal polynomial contrasts were used to evaluate the linear and quadratic effects of graded levels of dietary genistein on the parameters. Growth performance parameters were based on replicate as the experimental unit, while all other parameters were analysed on individual broilers. All results were expressed as mean \pm pooled SEM. A probability value of $P<0.05$ was statistically significant.

\section{Results}

Data for growth performance are presented in Table 2. On day 42, the bodyweight of broilers was increased in those that had received genistein at 400 and $600 \mathrm{mg} / \mathrm{kg}$ (linear, $P=0.004$; quadratic, $P=0.005$ ), while on day 58, no significant differences were found among any of the groups $(P>0.05)$. From three to six weeks of fattening, weight gain and daily weight gain of T2, T3, and T4 groups were higher than $\mathrm{C}$, with the linear and quadratic effects being observed, while up to day 58 in the T3 group $(600 \mathrm{mg} / \mathrm{kg})$, weight gain decreased significantly. For both experimental periods, total feed intake was not affected $(P>0.05)$ by genistein. Feed conversion ratio (FCR) from day 21 to day 42 was better in all groups that received genistein compared with the control, with a significant difference in T3 and T4 $(1.64,1.65$, respectively; linear, $P$ $=0.0001$ ). After extended fattening, up to 58 days, FCR was best in T4 (2.37), but this did not differ from the $\mathrm{T} 1$ and T2. However, supplementation with $600 \mathrm{mg} / \mathrm{kg}$ genistein had an adverse effect on FCR (2.88). 
Table 2 Effects of different levels of genistein supplementation on broiler performance at 42 and 58 days old

\begin{tabular}{|c|c|c|c|c|c|c|c|c|c|}
\hline \multirow{2}{*}{ Trait } & \multirow{2}{*}{$\begin{array}{l}\text { Age } \\
\text { (days) }\end{array}$} & \multicolumn{5}{|c|}{ Experimental group ${ }^{1}$} & \multirow{2}{*}{ SEM } & \multicolumn{2}{|c|}{ Contrasts, $P$-value } \\
\hline & & $\mathrm{C}$ & $\mathrm{T} 1$ & $\mathrm{~T} 2$ & T3 & $\mathrm{T} 4$ & & Linear & Quadratic \\
\hline \multirow[t]{3}{*}{ Weight } & 21 & 967 & 980 & 993 & 972 & 979 & 14.95 & 0.432 & 0.266 \\
\hline & 42 & $2623^{a}$ & $2727^{a}$ & $2847^{b}$ & $2781^{b}$ & $2772^{\mathrm{a}}$ & 86.37 & 0.004 & 0.005 \\
\hline & 58 & 4021 & 4029 & 4122 & 3835 & 4095 & 174.73 & 0.851 & 0.672 \\
\hline \multirow[t]{2}{*}{ Gain } & $21-42$ & $1656^{a}$ & $1747^{\mathrm{ab}}$ & $1854^{b}$ & $1809^{b}$ & $1793^{b}$ & 72.26 & 0.001 & 0.003 \\
\hline & $43-58$ & $1293^{a}$ & $1298^{a}$ & $1323^{a}$ & $1139^{b}$ & $1407^{a}$ & 82.65 & 0.559 & 0.021 \\
\hline \multirow[t]{2}{*}{ ADG } & $21-42$ & $82.81^{a}$ & $87.33^{a b}$ & $92.68^{b}$ & $90.45^{b}$ & $89.63^{b}$ & 3.61 & 0.001 & 0.003 \\
\hline & $43-58$ & $86.19^{a}$ & $86.51^{a}$ & $88.21^{\mathrm{a}}$ & $75.92^{b}$ & $93.78^{a}$ & 5.51 & 0.559 & 0.021 \\
\hline \multirow[t]{2}{*}{$\mathrm{FI}$} & $21-42$ & 3236 & 3133 & 3293 & 2964 & 2959 & 223.36 & 0.031 & 0.442 \\
\hline & $43-58$ & 3460 & 3251 & 3484 & 3282 & 3332 & 272.89 & 0.564 & 0.859 \\
\hline \multirow[t]{2}{*}{ FC } & $21-42$ & $1.96^{\mathrm{a}}$ & $1.79^{a b}$ & $1.78^{\mathrm{ab}}$ & $1.64^{b}$ & $1.65^{\mathrm{b}}$ & 0.12 & 0.0001 & 0.282 \\
\hline & $43-58$ & $2.68^{\mathrm{ab}}$ & $2.50^{\mathrm{ac}}$ & $2.63^{a b c}$ & $2.88^{\mathrm{b}}$ & $2.37^{c}$ & 0.16 & 0.310 & 0.051 \\
\hline
\end{tabular}

a,b,c Within a row, means with a common superscript do not differ at $P=0.05$

$1 \mathrm{C}$ : control group of broilers fed the basal diet; T1: basal diet supplemented with $200 \mathrm{mg} / \mathrm{kg}$ genistein; T2: basal diet supplemented with $400 \mathrm{mg} / \mathrm{kg}$ genistein; T3: basal diet supplemented with $600 \mathrm{mg} / \mathrm{kg}$ genistein; T4: basal diet supplemented with $800 \mathrm{mg} / \mathrm{kg}$ genistein

ADG: average daily gain, $\mathrm{FI}$ : feed intake, $\mathrm{FC}$ : feed conversion ratio

Dietary genistein supplement at $800 \mathrm{mg} / \mathrm{kg}$ significantly improved the spleen (linear, quadratic, $P$ $=0.0001$ ) and heart absolute and relative weights when birds were 42 days old, while in 58-day-old birds, these differences were not observed (Table 3).

Table 3 Effect of different levels of genistein supplementation on absolute and relative organ weights of broilers

\begin{tabular}{|c|c|c|c|c|c|c|c|c|c|}
\hline \multirow{2}{*}{ Organ } & \multirow{2}{*}{ Age } & \multicolumn{5}{|c|}{ Experimental group ${ }^{1}$} & \multirow{2}{*}{ SEM } & \multicolumn{2}{|c|}{ Contrasts, $P$-value } \\
\hline & & C & $\mathrm{T} 1$ & T2 & T3 & T4 & & Linear & Quadratic \\
\hline \multirow[t]{2}{*}{ Liver } & 42 days & 41.60 & 44.00 & 45.07 & 46.07 & 47.87 & 3.74 & 0.007 & 0.840 \\
\hline & 58 days & 63.07 & 60.07 & 58.40 & 57.20 & 56.60 & 0.41 & 0.057 & 0.588 \\
\hline \multirow[t]{2}{*}{ Spleen } & 42 days & $2.13^{a}$ & $2.07^{a}$ & $2.27^{\mathrm{a}}$ & $2.33^{a}$ & $3.87^{b}$ & 1.83 & 0.0001 & 0.0001 \\
\hline & 58 days & 3.80 & 3.93 & 3.87 & 3.80 & 3.40 & 0.12 & 0.303 & 0.320 \\
\hline \multirow[t]{2}{*}{ Heart } & 42 days & $12.27^{\mathrm{a}}$ & $12.73^{\mathrm{a}}$ & $14.67^{a b}$ & $15.47^{a b}$ & $17.33^{b}$ & 0.02 & 0.0001 & 0.587 \\
\hline & 58 days & 22.33 & 19.13 & 21.87 & 21.33 & 19.47 & 0.06 & 0.312 & 0.884 \\
\hline \multicolumn{10}{|c|}{ Relative weight (\% of body weight) } \\
\hline \multirow[t]{2}{*}{ Liver } & 42 days & 1.69 & 1.63 & 1.56 & 1.63 & 1.68 & 5.78 & 0.880 & 0.061 \\
\hline & 58 days & 1.57 & 1.49 & 1.42 & 1.49 & 1.38 & 0.64 & 0.017 & 0.690 \\
\hline \multirow[t]{2}{*}{ Spleen } & 42 days & $0.088^{a}$ & $0.077^{a}$ & $0.077^{a}$ & $0.084^{a}$ & $0.137^{b}$ & 2.45 & 0.0001 & 0.0001 \\
\hline & 58 days & 0.096 & 0.101 & 0.094 & 0.101 & 0.083 & 0.11 & 0.312 & 0.301 \\
\hline \multirow[t]{2}{*}{ Heart } & 42 days & $0.50^{\mathrm{ab}}$ & $0.47^{\mathrm{a}}$ & $0.51^{\mathrm{ab}}$ & $0.55^{\mathrm{ab}}$ & $0.61^{b}$ & 0.02 & 0.002 & 0.137 \\
\hline & 58 days & 0.55 & 0.47 & 0.53 & 0.56 & 0.47 & 0.05 & 0.302 & 0.679 \\
\hline
\end{tabular}

a,b Within a row, means with a common superscript do not differ at $P=0.05$

${ }^{1} \mathrm{C}$ : control group of broilers fed the basal diet; T1: basal diet supplemented with $200 \mathrm{mg} / \mathrm{kg}$ genistein; T2: basal diet supplemented with $400 \mathrm{mg} / \mathrm{kg}$ genistein; T3: basal diet supplemented with $600 \mathrm{mg} / \mathrm{kg}$ genistein; T4: basal diet supplemented with $800 \mathrm{mg} / \mathrm{kg}$ genistein 
Dietary supplementation with $200,400,600$ and $800 \mathrm{mg} / \mathrm{kg}$ genistein had no significant effect on the plasma cholesterol levels of the broilers at the end of both periods $(P>0.05)$ (Table 4). Genistein supplementation significantly decreased (linear, $P=0.0001$; quadratic, $P=0.022$ ) birds' triglyceride levels during the first finisher period (day 42) compared with the control group. In contrast, on day 58, the authors' measured negative effects on the birds' triglyceride levels in those animals that were supplemented with 600 and $800 \mathrm{mg} / \mathrm{kg}$.

Table 4 Plasma total cholesterol and triglycerides concentrations in broilers at 42 and 58 days old

\begin{tabular}{llllllllll}
\hline & & \multicolumn{9}{c}{ Experimental group $^{1}$} & \multicolumn{2}{c}{ Contrasts, $P$-value } \\
Constituent & Age & C & T1 & T2 & T3 & T4 & & Linear & Quadratic \\
\hline \multirow{2}{*}{ Cholesterol } & 42 days & 3.42 & 2.81 & 2.97 & 3.19 & 3.11 & 0.37 & 0.662 & 0.079 \\
& 58 days & 3.36 & 2.77 & 3.10 & 3.22 & 3.30 & 0.35 & 0.528 & 0.062 \\
Triglycerides & 42 days & $0.50^{\mathrm{a}}$ & $0.35^{\mathrm{b}}$ & $0.34^{\mathrm{b}}$ & $0.30^{\mathrm{b}}$ & $0.31^{\mathrm{b}}$ & 0.07 & 0.0001 & 0.022 \\
& 58 days & $0.31^{\mathrm{a}}$ & $0.40^{\mathrm{ab}}$ & $0.39^{\mathrm{ab}}$ & $0.42^{\mathrm{b}}$ & $0.43^{\mathrm{b}}$ & 0.05 & 0.002 & 0.207
\end{tabular}

a,b Within a row, means with a common superscript do not differ at $P=0.05$

${ }^{1} \mathrm{C}$ : control group of broilers fed the basal diet; T1: basal diet supplemented with $200 \mathrm{mg} / \mathrm{kg}$ genistein; T2: basal diet supplemented with $400 \mathrm{mg} / \mathrm{kg}$ genistein; T3: basal diet supplemented with $600 \mathrm{mg} / \mathrm{kg}$ genistein; T4: basal diet supplemented with $800 \mathrm{mg} / \mathrm{kg}$ genistein

There were no differences among treatments in the numbers of Lactobacilli in the caeca of birds supplemented with genistein or not in the 42-day-old birds, with the exception of $200 \mathrm{mg} / \mathrm{kg}$ genistein, in which the LAB count was lower (5.80 log CFU/g). However, on day 58, the number of LAB was increased (linear, $P=0.0001$ ) in the caeca of the groups that were supplemented with genistein at concentrations of 400,600 and $800 \mathrm{mg} / \mathrm{kg}(6.24,6.42,6.38 \mathrm{log}$ CFU/g, respectively (Figure 2).

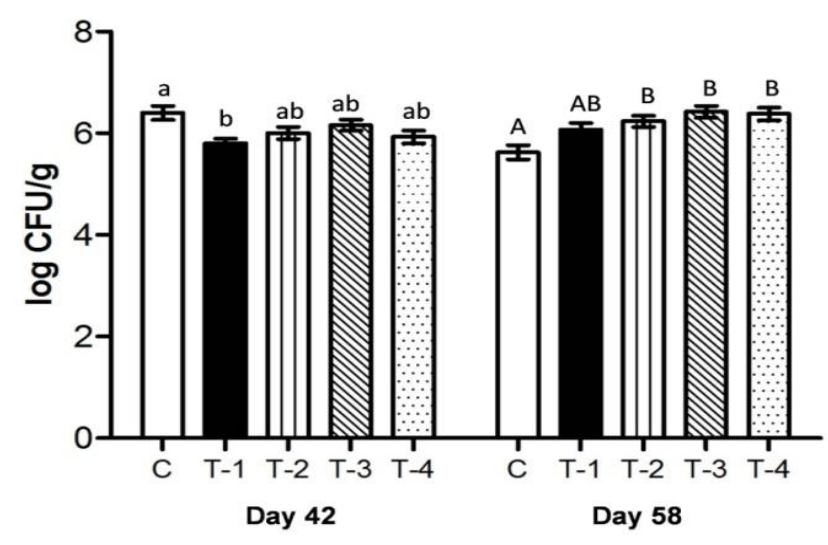

Figure 2 Caecal Lactobacillus populations in broilers fed diets without (C) or with $200 \mathrm{mg} / \mathrm{kg}$ (T1), $400 \mathrm{mg} / \mathrm{kg}$ (T2), $600 \mathrm{mg} / \mathrm{kg}$ (T3), and $800 \mathrm{mg} / \mathrm{kg}$ genistein at 42 and 58 days old

a,b(A,B) Bars with a common lowercase (uppercase) superscript do not differ at $P=0.05$ at 42 (58) days of age

In 42-day-old birds the villus height in the duodenum was higher in broilers fed diets with the addition of genistein (Table 5). The best effect was achieved by supplementation with $400 \mathrm{mg} / \mathrm{kg}$ (T2). Villus width was reduced significantly with the addition of 400,600 and $800 \mathrm{mg} / \mathrm{kg}$ genistein. Also, in all treatment groups, crypt depth was shorter and the villus height: crypt depth ratio was higher than those in the control 
group. After the second fattening period (day 58), genistein supplementation did not affect villus height, but it significantly reduced the villus width of the T4 group and the crypt depth of the T2, T3 and T4, and improved villus height: crypt depth ratio in the T4 group.

At 42 days, the effect of the genistein dose on the jejunal villus volume was somewhat inconsistent up to the concentration of $600 \mathrm{mg} / \mathrm{kg}$, while $800 \mathrm{mg} / \mathrm{kg}$ led to significantly depressed jejunal mucosa development. With prolonged genistein supplementation in the birds' diets, at 58 days positive effects on the villus height, villus width and the villus height: crypt depth ratio was measured in the jejunum, while the crypt depths were reduced significantly only with the inclusion of 200 and $800 \mathrm{mg} / \mathrm{kg}$ genistein.

Similar inconsistencies in the effect of high doses of genistein were found on the morphometric parameters in the ileum, in which the broilers fed the diets with genistein had significantly reduced villus height and villus height: crypt depth ratio, and these were the lowest for both fattening periods in the birds receiving $600 \mathrm{mg} / \mathrm{kg}$ genistein.

Table 5 Effect of different levels of genistein supplementation on intestinal morphometric parameters in broilers at 42 and 58 days old

\begin{tabular}{|c|c|c|c|c|c|c|c|c|c|}
\hline \multirow{2}{*}{ Structure } & \multirow{2}{*}{$\begin{array}{l}\text { Age } \\
\text { (in } \\
\text { days) }\end{array}$} & \multicolumn{5}{|c|}{ Experimental group ${ }^{1}$} & \multirow{2}{*}{ SEM } & \multicolumn{2}{|c|}{ Contrasts, $P$-value } \\
\hline & & C & $\mathrm{T} 1$ & T2 & T3 & $\mathrm{T} 4$ & & Linear & Quadratic \\
\hline \multicolumn{10}{|l|}{ Duodenum } \\
\hline \multirow{2}{*}{ Villus height $(\mu \mathrm{m})$} & 42 & $1197^{a}$ & $1212^{a}$ & $1284^{b}$ & $1226^{a b}$ & $1257^{\mathrm{ab}}$ & 36.57 & 0.011 & 0.111 \\
\hline & 58 & 996.1 & 962.8 & 964.1 & 944.5 & 969.2 & 33.34 & 0.129 & 0.091 \\
\hline \multirow{2}{*}{ Villus width $(\mu \mathrm{m})$} & 42 & $101.5^{a}$ & $101.7^{a}$ & $87.01^{\mathrm{b}}$ & $76.36^{c}$ & $79.48^{b}$ & 4.33 & 0.0001 & 0.169 \\
\hline & 58 & $77.57^{\mathrm{ab}}$ & $77.50^{\mathrm{ab}}$ & $81.36^{a}$ & $84.85^{a}$ & $72.85^{b}$ & 4.36 & 0.735 & 0.001 \\
\hline \multirow{2}{*}{ Crypt depth $(\mu \mathrm{m})$} & 42 & $162.9^{a}$ & $133.6^{\mathrm{b}}$ & $131.3^{\mathrm{b}}$ & $131.4^{\mathrm{b}}$ & $125.9^{\mathrm{b}}$ & 5.90 & 0.0001 & 0.0001 \\
\hline & 58 & $153.7^{\mathrm{a}}$ & $147.6^{\mathrm{a}}$ & $135.0^{\mathrm{b}}$ & $137.1^{\mathrm{b}}$ & $122.1^{\mathrm{c}}$ & 5.93 & 0.0001 & 0.757 \\
\hline \multirow{2}{*}{$\begin{array}{l}\text { Villus height: crypt } \\
\text { depth ratio }\end{array}$} & 42 & $7.48^{\mathrm{a}}$ & $9.10^{\mathrm{b}}$ & $9.86^{\mathrm{bc}}$ & $9.38^{\mathrm{bc}}$ & $10.10^{c}$ & 0.43 & 0.0001 & 0.0001 \\
\hline & 58 & $6.50^{\mathrm{a}}$ & $6.63^{\mathrm{a}}$ & $7.22^{\mathrm{a}}$ & $7.02^{\mathrm{a}}$ & $8.02^{\mathrm{b}}$ & 0.41 & 0.0001 & 0.168 \\
\hline \multicolumn{10}{|l|}{ Jejunum } \\
\hline \multirow{2}{*}{ Villus height $(\mu \mathrm{m})$} & 42 & $978.7^{a}$ & $950.6^{\mathrm{ac}}$ & $1132.0^{\mathrm{b}}$ & $991.4^{\mathrm{a}}$ & $880.1^{c}$ & 44.28 & 0.014 & 0.0001 \\
\hline & 58 & $812.9^{a}$ & $965.7^{b}$ & $960.4^{\mathrm{b}}$ & $938.6^{\mathrm{b}}$ & $904.0^{\mathrm{b}}$ & 46.91 & 0.021 & 0.0001 \\
\hline \multirow{2}{*}{ Villus width $(\mu \mathrm{m})$} & 42 & $81.21^{a}$ & $76.24^{\mathrm{ab}}$ & $74.28^{\mathrm{b}}$ & $75.16^{\mathrm{ab}}$ & $62.54^{c}$ & 3.78 & 0.0001 & 0.051 \\
\hline & 58 & $80.54^{\mathrm{a}}$ & $82.60^{\mathrm{ab}}$ & $88.00^{\mathrm{b}}$ & $87.83^{b}$ & $88.33^{b}$ & 3.66 & 0.0001 & 0.158 \\
\hline \multirow{2}{*}{ Crypt depth $(\mu \mathrm{m})$} & 42 & $98.34^{\mathrm{a}}$ & $104.90^{\mathrm{ab}}$ & $108.60^{\mathrm{bc}}$ & $121.70^{c}$ & $114.20^{c}$ & 4.65 & 0.0001 & 0.018 \\
\hline & 58 & $148.9^{a}$ & $134.7^{b c}$ & $142.2^{\mathrm{ab}}$ & $143.5^{\mathrm{ab}}$ & $127.4^{c}$ & 5.26 & 0.0001 & 0.254 \\
\hline \multirow{2}{*}{$\begin{array}{l}\text { Villus height: crypt } \\
\text { depth ratio }\end{array}$} & 42 & $10.09^{a c}$ & $9.17^{\mathrm{a}}$ & $10.61^{c}$ & $8.21^{b}$ & $7.75^{b}$ & 0.53 & 0.0001 & 0.001 \\
\hline & 58 & $5.51^{\mathrm{a}}$ & $7.26^{\mathrm{b}}$ & $6.85^{\mathrm{b}}$ & $6.51^{\mathrm{b}}$ & $7.13^{b}$ & 0.45 & 0.0001 & 0.004 \\
\hline \multicolumn{10}{|l|}{ Ileum } \\
\hline \multirow{2}{*}{ Villus height $(\mu \mathrm{m})$} & 42 & $563.3^{a}$ & $541.5^{\mathrm{ab}}$ & $542.3^{a b}$ & $503.6^{\mathrm{b}}$ & $503.9^{b}$ & 22.93 & 0.0001 & 0.907 \\
\hline & 58 & $590.1^{a}$ & $505.9^{b}$ & $531.1^{b}$ & $492.3^{b}$ & $493.7^{b}$ & 25.73 & 0.0001 & 0.014 \\
\hline \multirow{2}{*}{ Villus width $(\mu \mathrm{m})$} & 42 & $66.56^{a}$ & $70.99^{b}$ & $60.23^{c}$ & $65.19^{a}$ & $64.14^{\mathrm{ac}}$ & 2.46 & 0.003 & 0.249 \\
\hline & 58 & $65.53^{a}$ & $71.52^{b}$ & $63.95^{\mathrm{a}}$ & $72.85^{b}$ & $74.28^{b}$ & 2.80 & 0.0001 & 0.120 \\
\hline \multirow{2}{*}{ Crypt depth $(\mu \mathrm{m})$} & 42 & $118.5^{\mathrm{a}}$ & $135.1^{\mathrm{b}}$ & $141.8^{\mathrm{b}}$ & $139.5^{\mathrm{b}}$ & $120.1^{\mathrm{a}}$ & 4.75 & 0.249 & 0.0001 \\
\hline & 58 & $131.3^{\mathrm{ab}}$ & $130.4^{\mathrm{ab}}$ & $136.3^{a}$ & $136.1^{\mathrm{a}}$ & $125.1^{b}$ & 4.69 & 0.317 & 0.001 \\
\hline \multirow{2}{*}{$\begin{array}{l}\text { Villus height: crypt } \\
\text { depth ratio }\end{array}$} & 42 & $4.79^{a}$ & $4.06^{b}$ & $3.84^{\mathrm{bc}}$ & $3.63^{c}$ & $4.22^{b}$ & 0.22 & 0.0001 & 0.0001 \\
\hline & 58 & $4.54^{\mathrm{a}}$ & $3.90^{\mathrm{b}}$ & $3.93^{b}$ & $3.63^{b}$ & $3.97^{b}$ & 0.23 & 0.0001 & 0.0001 \\
\hline
\end{tabular}

a,b,c Different lowercase superscript letters after means in the same row indicate differences $(P<0.05)$ among groups

${ }^{1} \mathrm{C}$ : control group of broilers fed the basal diet; T1: basal diet supplemented with $200 \mathrm{mg} / \mathrm{kg}$ genistein; T2: basal diet supplemented with $400 \mathrm{mg} / \mathrm{kg}$ genistein; T3: basal diet supplemented with $600 \mathrm{mg} / \mathrm{kg}$ genistein; T4: basal diet supplemented with $800 \mathrm{mg} / \mathrm{kg}$ genistein 
In 42-day-old birds, genistein supplementation at concentrations of 200,400 and $600 \mathrm{mg} / \mathrm{kg}$ resulted in significantly improved absolute weight and ash contents of the birds' tibias (Table 6). Calcium content in the tibias was significantly increased by 200 and $400 \mathrm{mg} / \mathrm{kg}$ genistein supplementation on day 42 , while on day 58 , these levels led to a decrease in $\mathrm{Ca}$. The most pronounced decrease in $\mathrm{P}$ content in the birds' tibias was observed with 600 and $800 \mathrm{mg} / \mathrm{kg}$ genistein in the 42-day-old birds, while prolonged dietary supplementation resulted in an increase in P content in the $400 \mathrm{mg} / \mathrm{kg}$ genistein group that did not differ from the control group of birds.

Table 6 Effect of different levels of genistein supplementation on absolute and relative weight and mineral content of tibia of broilers at 42 and 58 days old

\begin{tabular}{|c|c|c|c|c|c|c|c|c|c|}
\hline \multirow{2}{*}{ Characteristic } & \multirow{2}{*}{ Age } & \multicolumn{5}{|c|}{ Experimental group ${ }^{1}$} & \multirow{2}{*}{ SEM } & \multicolumn{2}{|c|}{ Contrasts, $P$-value } \\
\hline & & C & T1 & T2 & T3 & T4 & & Linear & Quadratic \\
\hline \multirow{2}{*}{ Weight (g) } & 42 days & $12.00^{\mathrm{a}}$ & $14.67^{b c}$ & $15.33^{b}$ & $14.00^{\mathrm{bc}}$ & $13.33^{a c}$ & 0.97 & 0.153 & 0.0001 \\
\hline & 58 days & 17.89 & 18.89 & 19.00 & 17.56 & 20.00 & 1.83 & 0.272 & 0.666 \\
\hline \multirow{2}{*}{$\begin{array}{l}\text { Relative weight } \\
\text { (\% BW) }\end{array}$} & 42 days & 0.507 & 0.552 & 0.550 & 0.489 & 0.469 & 0.05 & 0.077 & 0.042 \\
\hline & 58 days & 0.430 & 0.457 & 0.437 & 0.449 & 0.483 & 0.06 & 0.232 & 0.623 \\
\hline \multirow{2}{*}{ Ash (\%) } & 42 days & $42.15^{\mathrm{a}}$ & $49.19^{b}$ & $49.27^{b}$ & $44.24^{c}$ & $41.62^{\mathrm{a}}$ & 0.90 & 0.0001 & 0.0001 \\
\hline & 58 days & $42.96^{a c}$ & $36.77^{b}$ & $39.05^{b c}$ & $40.94^{c}$ & $41.32^{\mathrm{ac}}$ & 1.60 & 0.702 & 0.0001 \\
\hline \multirow{2}{*}{$\mathrm{Ca}(\%)$} & 42 days & $15.32^{\mathrm{a}}$ & $17.33^{b}$ & $16.75^{c}$ & $15.53^{\mathrm{a}}$ & $14.24^{d}$ & 0.26 & 0.0001 & 0.0001 \\
\hline & 58 days & $14.91^{\mathrm{a}}$ & $12.95^{\mathrm{bc}}$ & $13.66^{c}$ & $14.35^{\mathrm{a}}$ & $14.74^{\mathrm{ac}}$ & 0.67 & 0.272 & 0.0001 \\
\hline \multirow{2}{*}{$\mathrm{P}(\%)$} & 42 days & $8.23^{a b}$ & $8.60^{\mathrm{a}}$ & $8.34^{a}$ & $7.63^{b}$ & $7.55^{\mathrm{b}}$ & 0.38 & 0.0001 & 0.045 \\
\hline & 58 days & $7.35^{\mathrm{ab}}$ & $6.68^{\mathrm{a}}$ & $8.13^{b}$ & $7.28^{\mathrm{a}}$ & $7.24^{\mathrm{a}}$ & 0.43 & 0.540 & 0.163 \\
\hline
\end{tabular}

a,b,c Within a row, means with a common superscript do not differ at $P=0.05$

1 C: basal diet; T1: basal diet supplemented with $200 \mathrm{mg} / \mathrm{kg}$ genistein; T2: basal diet supplemented with $400 \mathrm{mg} / \mathrm{kg}$ genistein; T3: basal diet supplemented with $600 \mathrm{mg} / \mathrm{kg}$ genistein; T4: basal diet supplemented with $800 \mathrm{mg} / \mathrm{kg}$ genistein

Ca: calcium, P: Phosphorus

\section{Discussion}

The effects of isoflavones, including genistein, on bodyweight, weight gain, feed intake, and feed conversion ratio in poultry are variable. Diets supplemented with low to moderate levels $(20$ to $80 \mathrm{mg} / \mathrm{kg})$ of genistein positively affected weight gain and FCR values of broilers during a six-week feeding period (Rasouli \& Jahanian, 2015; Lv et al., 2018). Onderci et al. (2004) observed significantly improved growth performance as a result of the addition of 400 and $800 \mathrm{mg} / \mathrm{kg}$ genistein to a quail diet. However, some studies found dietary supplementation with purified genistein did not influence the growth rate or FCR of broiler chickens (Kamboh \& Zhu, 2013a; Kamboh \& Zhu, 2014; lqbal et al., 2014). The results of the present study showed improved performances after 21 days of high dose genistein treatment, but the $600 \mathrm{mg}$ genistein $/ \mathrm{kg}$ diet for 37 days led to a significant decrease in weight gain and increase in FCR. Rasouli and Jahanian (2019) found similar discrepancies in production results during various growth periods, in which low to moderate levels $(20-80 \mathrm{mg} / \mathrm{kg}$ ) and moderate levels $(40-80 \mathrm{mg} / \mathrm{kg})$ of genistein significantly increased average daily feed intake and weight gain after starter and grower periods, respectively, while high genistein levels $(160-320 \mathrm{mg} / \mathrm{kg}$ ) did not cause differences in these parameters or even worsened FCR during the starter period. In agreement with the present findings, Jiang et al. (2007) obtained inconsistency in performances of 43- to 63-day-old broilers with tenfold lower doses of isoflavone. Importantly, Qian and Sun (2009) showed that soy isoflavone aglycones could exhibit potentially adverse effects if they were not well balanced in the feed. Previous studies revealed the effect of low to high supplement doses of various isoflavone preparations (Payne et al., 2001; Gjorgovska et al., 2014; 2016; Shiralinezhad \& Shakouri; 2017), combinations and purified isoflavones (Kamboh \& Zhu, 2013a; 2014; Onderci et al., 2004), and isoflavone glucosidase (Qian \& Sun, 2009) in broiler chicks, laying hens, quails, immune-challenged animals (Rasouli \& Jahanian, 2015; Zhu et al., 2015), and animals exposed to heat stress (Onderci et al., 2004; Sahin et al., 2007). These studies indicate that various factors - including kinds and forms of isoflavones, their interactions, dose, treatment duration, and bird age, gender, individual metabolism and health status - 
largely determine growth-promoting effects, which are more evident in animals that are subjected to environmental stress.

In the present study the highest level of genistein significantly increased spleen and heart absolute and relative weights, with no effect on the liver weight for both finishing periods. As immune-modulatory substances, flavonoids could cause variations in the size of the main lymphatic organs in poultry. The size of these organs is considered a good indicator of changes in the degree of lymphocyte proliferation and immune responses (Kamboh et al., 2015; Rasouli \& Jahanian, 2015). Rasouli and Jahanian (2019) found that dietary genistein did not affect the relative heart weight in broilers, which is not in accordance with the present findings. By increasing relative heart weight, dietary flavonoid quercetin induced a beneficial effect on the cardiovascular system of broilers (Goliomytis et al., 2014). Unfortunately, it was confirmed that the genetic selection of broilers for weight gain led to reduced relative heart size, which resulted in insufficient oxygen supply to tissues and development of metabolic disorders such as ascites and sudden death syndrome (Havenstein et al., 1994). Further research is needed to determine by which mechanisms and to what extent genistein has the potential to prevent these syndromes.

Deficiency in oestrogen production could lead to changes in the lipid and lipoprotein profiles and consequently to increased serum cholesterol level (Setchell \& Cassidy, 1999). Some studies suggested that plant isoflavones, by acting like oestrogen agonists, were involved in the cholesterol-lowering effect (Anthony, 2000; Ali et al., 2004), while this effect was not found in others (Dewell et al., 2002; Nestel et al., 1999). This variability is because of the multifactorial mechanism through which cholesterol absorption and metabolism are modulated by enzyme regulation and depends primarily on the type and dose of isoflavone, and initial serum cholesterol level (Anderson et al., 1995). Since the main enzymes that are involved in cholesterol production are 3-hydroxy-3-methylglutaryl-coenzyme A (HMG CoA) synthase and reductase (Pakalapati et al., 2009), Kamboh and Zhu (2013b) showed a dose-dependent decrease in serum cholesterol and triglyceride levels in broilers fed diets supplemented with genistein and hesperidin, indicating their inhibitory effects on HMG-CoA reductase. In addition, the cholesterol-lowering effect is observed mainly in studies with soybean extract (Anderson et al., 1995; Yilmaz et al., 2008). The results of authors who used purified phytoestrogens, along with the current findings, showed no effect on cholesterol level (Dewell et al., 2002; Onderci et al., 2004). In contrast, lqbal et al. (2014) and Rasouli and Jahanian (2019) found decreased plasma cholesterol levels in genistein-supplemented groups after a six-week feeding period. In terms of plasma triglyceride levels, an increase was observed in ovariectomized rats fed red clover extract rich in isoflavones (Pakalapati et al., 2009). The results from the present study support earlier findings that as a selective oestrogen receptor modulator, genistein differentially influences plasma lipid levels (Pakalapati et al., 2009). After 21 days of genistein supplementation, the authors measured a lowering plasma lipid effect, while in broilers with prolonged genistein supplementation at 600 and $800 \mathrm{mg} / \mathrm{kg}$, adverse effects were measured on serum triglycerides levels (i.e. triglycerides increased).

Changes of intestinal morphology in terms of enlargement of villus length and width along with a decrease in crypt depth and a higher villus/crypt ratio are related to improved intestinal function owing to the greater surface area, better expression of brush border enzymes, and transport systems that allow higher nutrient absorption and a lower rate of epithelial cell turnover (Awad et al., 2011; Kamboh \& Zhu, 2014). The present study showed that genistein induced a positive effect on villus height, crypt depth and villus/crypt ratio in the duodenum in six-week-old broilers. Since the duodenum is the major site of nutrient digestion and absorption (Qian et al., 2012), the current observed higher growth performance indicators in this age of birds could partly be a result of hypertrophied duodenal villi. Previous studies showed that supplementation with a genistein preparation and with purified genistein for 21 and 28 days, respectively, during starter and grower periods significantly improved the jejunal mucosal morphometry of broiler chickens (Shiralinezhad \& Shakouri, 2017; Rasouli \& Jahanian, 2019). In the present study, this effect was not observed during the finisher period after 21 days, but only after prolonged genistein administration (37 days in total). The exact mechanism by which flavonoids affect intestinal mucosal structure is still unknown, but probably it could be attributed to their antioxidative activity against intestinal apoptotic and pro-oxidant factors (Awad et al., 2011; Kamboh et al., 2015). In addition, in the present study, genistein treatment impaired ileal morphometric features for both finishing periods in comparison with the control group. This suggests that the better production results that were obtained in broilers that received genistein supplementation were not related directly to the improved gut morphology, but to mechanisms such as enhanced antioxidative status, increased nutrient digestibility and depression of harmful intestinal microbial populations, with a shift to more beneficial ones (Onderci et al., 2004; Jiang et al., 2007; Qian et al., 2012; Rasouli \& Jahanian, 2015; Shiralinezhad \& Shakouri, 2017; Rasouli \& Jahanian, 2019).

The authors observed that longer high-level genistein treatments led to an overall significant increase in caecal LAB count by about $0.73 \mathrm{log}$ CFU/g compared with the control group. It was shown that higher genistein levels were more effective in reducing the ileal number of Salmonella and $E$. coli in broilers 
(Rasouli \& Jahanian, 2019). In addition to the antibacterial activity of isoflavones, which is well documented (Cushnie \& Lamb, 2005), their potentiality as prebiotic substances that favour the growth of Lactobacillus was reported in postmenopausal women (Clavel et al., 2005) and piglets (Yao et al., 2004).

The lower doses of genistein $(200$ and $400 \mathrm{mg} / \mathrm{kg}$ ) that were used in this study had a positive effect on tibia wet weight, ash and $\mathrm{Ca}$ content after 21 days of administration, while prolonged genistein supplementation led to decreased ash and Ca contents in the birds' tibias. Stevenson (2012) found that daily gavage of $10-40 \mathrm{mg}$ of genistein for 14 days did not influence wet, dry and ashed femur weights, and increasing doses of daily injected genistein had a depressing effect on the wet femur weights in female broiler chicks. Furthermore, a high injected dose of genistein had a beneficial effect on bone quality in aged laying hens, while medium doses exhibited a negative effect (Stevenson, 2012). This suggests that the effect of genistein on bone quality depends on the age and bone type of the birds, and the dose and method of administration (Stevenson, 2012). Significantly higher wet tibia weights of birds that received $400 \mathrm{mg} / \mathrm{kg}$ genistein could be explained by their larger body size in the present study. However, genistein partially enables a decrease in bone reabsorption by interaction with nuclear oestrogen receptors with higher affinity to ER- $\beta$, which are more widely distributed in bone tissue (Morabito et al., 2002). Moreover, soy isoflavones affect calcium metabolism by increasing its absorption from the intestines (Sahin et al., 2007). This indicates that the differences in wet tibia weight and mineral content in the present study could result from genistein's estrogenic effects on the amount and composition of bone marrow (Stevenson, 2012). In addition to direct hormonal action, genistein's strong inhibitory effect on osteoclast activity and mitogenic effect on osteoblasts could be attributed to inhibition of protein tyrosine kinases, which leads to increased alkaline phosphatase activity and bone calcium content (Gao \& Yamaguchi, 2000). However, the results of the present study showed that higher doses of genistein, including lower levels during prolonged fattening, were not effective in reducing bone loss in relation to the control group of broilers. These findings are consistent with previous studies in which biphasic dose-dependent responses of genistein were observed, meaning that higher doses of genistein were less effective than lower ones, which tended to enhance the rate of bone formation (Anderson et al., 1998; Stevenson, 2012).

\section{Conclusions}

Genistein supplementation of broilers' diet for three weeks during the commercial finishing phase exhibited a beneficial effect, while its prolonged administration did not cause significant improvements. However, further studies are needed to rationalize the use of these high genistein doses, taking into account the immune response, the cardiovascular system, gut microbiota, and the safety, quality and sustainability of the broiler meat and the cost-effectiveness of such production.

\section{Acknowledgments}

This article was supported by the Ministry of Education, Science and Technological Development of the Republic of Serbia via the project titled 'Selected biological hazards to the safety/quality of food of animal origin and the control measures from farm to consumer' (TR 31034).

\section{Authors' Contributions}

$M G$ designed the investigation, performed the analysis, and wrote the paper. MB helped performed analyses and co-wrote the paper. AR performed histological analyses. DS analysed and interpreted the performance results. VDj carried out chemical analysis. MR collected data and performed biochemistry analysis. MZB and RM conceived the investigation together with the first author and helped collect and analyse the data.

\section{Conflict of Interest Declaration}

The authors declare they have no potential conflicts of interests.

\section{References}

Ali, A.A., Velasquez, M.T., Hansen, C.T., Mohamed, A.I. \& Bhathena, S.J., 2004. Effects of soybean isoflavones, probiotics, and their interactions on lipid metabolism and endocrine system in an animal model of obesity and diabetes. J. Nutr. Biochem. 15(10), 583-590. DOI: 10.1016/j.jnutbio.2004.04.005

Anderson, J.J.B., Ambrose, W.W. \& Garner, S.C., 1998. Biphasic effects of genistein on bone tissue in the ovariectomized, lactating rat model. SEBM 217(3), 345-350. DOI: 10.3181/00379727-217-44243

Anderson, J.W., Johnstone, B.M. \& Cook-Newell, M.E., 1995. Meta-analysis of the effects of soy protein intake on serum lipids. N. Engl. J. Med. 333(5), 276-282. DOI: 10.1056/NEJM199508033330502

Anthony, M.S., 2000. Soy and cardiovascular disease: cholesterol lowering and beyond. J. Nutr. 130(3), 662-663. DOI: 10.1093/jn/130.3.662S

Aptekmann, K.P., Artoni, S.B., Stefanini, M.A. \& Orsi, M.A., 2001. Morphometric analysis of the intestine of domestic quails (Coturnix coturnix japonica) treated with different levels of dietary calcium. Anat. Histol. Embryol. 30(5), 277-280. DOI: 10.1046/j.1439-0264.2001.00331.x 
Awad, W.A., Ghareeb, K., \& Böhm, J., 2011. Evaluation of the chicory inulin efficacy on ameliorating the intestinal morphology and modulating the intestinal electrophysiological properties in broiler chickens. J. Anim. Physiol. Anim. Nutr. 95(1), 65-72. DOI: 10.1111/j.1439-0396.2010.00999.x

Clavel, T., Fallani, M., Lepage, P., Levenez, F., Mathey, J., Rochet, V., Sérézat, M., Sutren, M., Henderson, G., Bennetau-Pelissero, C., Tondu, F., Blaut, M., Doré, J. \& Coxam, V., 2005. Isoflavones and functional foods alter the dominant intestinal microbiota in postmenopausal women. J. Nutr. 135(12), 2786-2792. DOI: $10.1093 / \mathrm{jn} / 135.12 .2786$

Cushnie, T.T. \& Lamb, A.J., 2005. Antimicrobial activity of flavonoids. Int. J. Antimicrob. Agents 26(5), 343-356. DOI: 10.1016/j.jantimicag.2005.09.002

Dewell, A., Hollenbeck, C.B. \& Bruce, B., 2002. The effects of soy-derived phytoestrogens on serum lipids and lipoproteins in moderately hypercholesterolemic postmenopausal women. J. Clin. Endocrinol. Metab. 87(1), 118121. DOI: $10.1210 /$ jcem.87.1.8155

Dixon, R.A. \& Ferreira, D., 2002. Molecules of interest: Genistein. Phytochemistry 60, 205-211. DOI: 10.1016/S00319422(02)00116-4

Ganai, A.A. \& Farooqi, H., 2015. Bioactivity of genistein: A review of in vitro and in vivo studies. Biomed. Pharmacother. 76, 30-38. DOI: 10.1016/j.biopha.2015.10.026

Gao, Y.H. \& Yamaguchi, M., 2000. Suppressive effect of genistein on rat bone osteoclasts: Involvement of protein kinase inhibition and protein tyrosine phosphatase activation. Int. J. Mol. Med. 5(3), 261-268. DOI: 10.3892/ijmm.5.3.261

Gjorgovska, N., Filev, K., Pavlova, V. \& Levkov, V., 2014. Effects of the soy isoflavones on the growth and the exterior development of the ISA Brown pullets. Emir. J. Food Agric. 26(9), 822-827. DOI: 10.9755/ejfa.v26i9.17535

Gjorgovska, N., Filev, K., Levkov, V., Nastova, R. \& Jusufi, E., 2016. Effects of dietary supplementation with isoflavones on exterior development and tibia bone quality of laying hens. Slovak J. Anim. Sci. 112-115.

Goliomytis, M., Tsoureki, D., Simitzis, P.E., Charismiadou, M.A., Hager-Theodorides, A.L. \& Deligeorgis, S.G., 2014. The effects of quercetin dietary supplementation on broiler growth performance, meat quality, and oxidative stability. Poult. Sci. 93(8), 1957-1962. DOI: 10.3382/ps.2013-03585

Havenstein, G.B., Ferket, P.R., Scheideler, S.E. \& Rives, D.V., 1994. Carcass composition and yield of 1991 vs 1957 broilers when fed "typical" 1957 and 1991 broiler diets. Poult. Sci. 73(12), 1795-1804. DOI: 10.3382/ps.0731795

Iqbal, M.F., Yu-Heng, L., Malik, M.H. \& Wei-Yun, Z., 2014. Evaluation of genistein mediated growth, metabolic and antiinflammatory responses in broilers. Pakistan J. Zool. 46(2), 317-327.

ISO 5983-1:2005. Animal feeding stuffs - Determination of nitrogen content and calculation of crude protein content Part 1: Kjeldahl method.

ISO 5984:2002. Animal feeding stuffs - Determination of crude ash.

ISO 6490-1:1985. Animal feeding stuffs - Determination of calcium content - Part 1: Titrimetric method.

ISO 6491:1998. Animal feeding stuffs - Determination of phosphorus content - Spectrometric method.

ISO 6492:1999. Animal feeding stuffs - Determination of fat content.

ISO 6496:1999. Animal feeding stuffs - Determination of moisture and other volatile matter content.

ISO 6865:2000. Animal feeding stuffs - Determination of crude fibre content - Method with intermediate filtration.

ISO 6869:2000. Animal feeding stuffs - Determination of the contents of calcium, copper, iron, magnesium, manganese, potassium, sodium and zinc - Method using atomic absorption spectrometry.

Jiang, Z.Y., Jiang, S.Q., Lin, Y.C., Xi, P.B., Yu, D.Q. \& Wu, T.X., 2007. Effects of soybean isoflavone on growth performance, meat quality, and antioxidation in male broilers. Poult. Sci. 86(7), 1356-1362. DOI: $10.1093 / p s / 86.7 .1356$

Kamboh, A.A. \& Zhu, W.Y., 2013a. Individual and combined effects of genistein and hesperidin supplementation on meat quality in meat-type broiler chickens. J. Sci. Food Agric. 93(13), 3362-3367. DOI: 10.1002/jsfa.6185

Kamboh, A.A. \& Zhu, W.Y., 2013b. Effect of increasing levels of bioflavonoids in broiler feed on plasma anti-oxidative potential, lipid metabolites, and fatty acid composition of meat. Poult. Sci. 92(2), 454-461. DOI: 10.3382/ps.201202584

Kamboh, A.A. \& Zhu, W.Y., 2014. Individual and combined effects of genistein and hesperidin on immunity and intestinal morphometry in lipopolysacharide-challenged broiler chickens. Poult. Sci. 93(9), 2175-2183. DOI: 10.3382/ps.2014-03971

Kamboh, A.A., Arain, M.A., Mughal, M.J., Zaman, A., Arain, Z.M. \& Soomro, A.H., 2015. Flavonoids: Health promoting phytochemicals for animal production-A review. J. Anim. Health Prod. 3(1), 6-13. DOI: 10.14737/journal.jahp/2015/3.1.6.13

Kamboh, A.A., Leghari, R.A., Khan, M.A., Kaka, U., Naseer, M., Sazili, A.Q. \& Malhi, K.K., 2019. Flavonoids supplementation-An ideal approach to improve quality of poultry products. Worlds Poult. Sci. J. 75(1), 115-126. DOI: $10.1017 /$ S0043933918000703

Lv, Z., Fan, H., Zhang, B., Xing, K. \& Guo, Y., 2018. Dietary genistein supplementation for breeders and their offspring improves the growth performance and immune function of broilers. Sci. Rep. 8(1), 5161. DOI: 10.1038/s41598018-23530-z

Markovic, R., Baltic, M.Z., Pavlovic, M., Glisic, M., Radulovic, S., Djordjevic, V. \& Sefer, D., 2015. Isoflavones - from biotechnology to functional foods. Procedia Food Sci. 5, 176-179. DOI: 10.1016/j.profoo.2015.09.050

Morabito, N., Crisafulli, A., Vergara, C., Gaudio, A., Lasco, A., Frisina, N., D'Anna, R., Corrado, F., Pizzoleo, M.A., Cincotta, M., Altavilla, D., lentile, R. \& Altavilla, D., 2002. Effects of genistein and hormone-replacement therapy on bone loss in early postmenopausal women: a randomized double-blind placebo-controlled study. J. Bone Miner. Res. 17(10), 1904-1912. DOI: 10.1359/jbmr.2002.17.10.1904

NRC, 1994. Nutrient requirements of poultry. 9th edition. National Academy Press, Washington, DC, USA 
Nestel, P.J, Pomeroy, S., Kay, S., Komesaroff, P., Behrsing, J., Cameron, D.L. \& West, L., 1999. Isoflavones from red clover improve systemic arterial compliance but not plasma lipids in menopausal women. J. Clin. Endocrinol. Metab. 84, 895-898. DOI: 10.1210/jcem.84.3.5561

Onderci, M., Sahin, K., Sahin, N., Gursu, M.F., Doerge, D., Sarkar, F.H. \& Kucuk, O., 2004. The effect of genistein supplementation on performance and antioxidant status of Japanese Quail under heat stress. Arch. Anim. Nutr. 58(6), 463-471. DOI: 10.1080/00039420400020017

Orčić, D., Francišković, M., Bekvalac, K., Svirčev, E., Beara, I., Lesjak, M. \& Mimica-Dukić, N., 2014. Quantitative determination of plant phenolics in Urticadioica extracts by high-performance liquid chromatography coupled with tandem mass spectrometric detection. Food Chem. 143, 48-53. DOI: 10.1016/j.foodchem.2013.07.097

Pakalapati, G., Li, L., Gretz, N., Koch, E. \& Wink, M., 2009. Influence of red clover (Trifolium pratense) isoflavones on gene and protein expression profiles in liver of ovariectomized rats. Phytomedicine 16(9), 845-855. DOI: 10.1016/j.phymed.2009.03.003

Payne, R.L., Bidner, T.D., Southern, L.L. \& McMillin, K.W., 2001. Dietary effects of soy isoflavones on growth and carcass traits of commercial broilers. Poult. Sci. 80(8), 1201-1207. DOI: 10.1016/j.phymed.2009.03.003

Qian, L.C. \& Sun, J.Y., 2009. Effect of $\beta$-glucosidase as a feed supplementary on the growth performance, digestive enzymes and physiology of broilers. Asian-Australas. J. Anim. Sci. 22(2), 260-266. DOI:10.5713/ajas.2009.80416

Qian, L.C., Sun, J.Y. \& Fu, S.J., 2012. Effect of $\beta$-glucosidase on the meat quality and digestibility in broilers. J. Anim. Physiol. Anim. Nutr. 96(2), 270-274. DOI: 10.1111/j.1439-0396.2011.01148.x

Rasouli, E. \&Jahanian, R., 2015. Improved performance and immunological responses as the result of dietary genistein supplementation of broiler chicks. Animal 9(9) 1473-1480. DOI: 10.1017/S1751731115000853

Rasouli, E. \& Jahanian, R., 2019. Comparative effects of genistein and antibiotics on performance, meat oxidative stability, jejunal morphology, and ileal microbial community in broiler chicks. Anim. Feed Sci. Tech. 256, 114-153. DOI: 10.1016/j.anifeedsci.2019.03.005

Sahin, N., Onderci, M., Balci, T.A., Cikim, G., Sahin, K. \& Kucuk, O., 2007. The effect of soy isoflavones on egg quality and bone mineralisation during the late laying period of quail. Br. Poult. Sci. 48(3), 363-369. DOI: $10.1080 / 00071660701341971$

Setchell, K.D. \& Cassidy, A., 1999. Dietary isoflavones: biological effects and relevance to human health. J. Nutr. 129(3), 758-767. DOI: 10.1093/jn/129.3.758S

Shiralinezhad, A. \& Shakouri, M.D., 2017. Improvement of growth performance and intestinal digestive function in broiler chickens by supplementation of soy isoflavone in corn-soy diet. J. Anim. Plant Sci. 27(1), 28-33.

Smirnov, A., Perez, R., Ami,T., Romach, E., Sklan, D. \& Uni, Z., 2005. Mucin dynamics and microbial populations in chicken small intestine are changed by dietary probiotic and antibiotic growth promoter supplementation. J. Nutr. 135(2), 187-192. DOI: 10.1093/jn/135.2.187

Stevenson, L., 2012. The estrogenic effects of the soy phytoestrogen genistein on the liver and bone of chickens. Doctoral dissertation. Auburn University, Auburn, Alabama. http://hdl.handle.net/10415/3084

Vantress, C., 2012. Cobb broiler management guide. Cobb-Vantress, Siloam Springs, AR, USA.

Wallace, R.J., Oleszek, W., Franz, C., Hahn, I., Baser, K.H.C., Mathe, A. \& Teichmann, K., 2010. Dietary plant bioactives for poultry health and productivity. Brit. Poult. Sci. 51(4), 461-487. DOI:10.1080/00071668.2010.506908

Yamabayashi, S., 1987. Periodic acid-Schiff-Alcian blue: A method for the differential staining of glycoproteins. Histochem. J. 19(10-11), 565-571. DOI: 10.1007/BF01687364

Yao, W., Wei-Yun, Z., Han, Z.K., Williams, B.A., Tamminga, S. \& Akkermans, A.D.L., 2004. Daidzein increased the density but not composition of Lactobacillus community in piglet digesta during in vitro fermentation as revealed by DGGE and dilution PCR. Reprod. Nutr. Dev. 44, 17.

Yilmaz, O., Guvenc, M., Cetintas, B., Tuzcu, M., Dayangac, A. \& Sahin, K., 2008. Effects of isoflavones supplementation on cholesterol and fatty acid levels of muscle and liver tissues of quail. J. Anim. Vet. Adv. 7, 1444-1449.

Zhu, C., Wu, Y., Jiang, Z., Zheng, C., Wang, L., Yang, X., Ma, X., Gao, K. \& Hu, Y., 2015. Dietary soy isoflavone attenuated growth performance and intestinal barrier functions in weaned piglets challenged with lipopolysaccharide. Int. Immunopharmacol, 28(1), 288-294. DOI: 10.1016/j.intimp.2015.04.054 